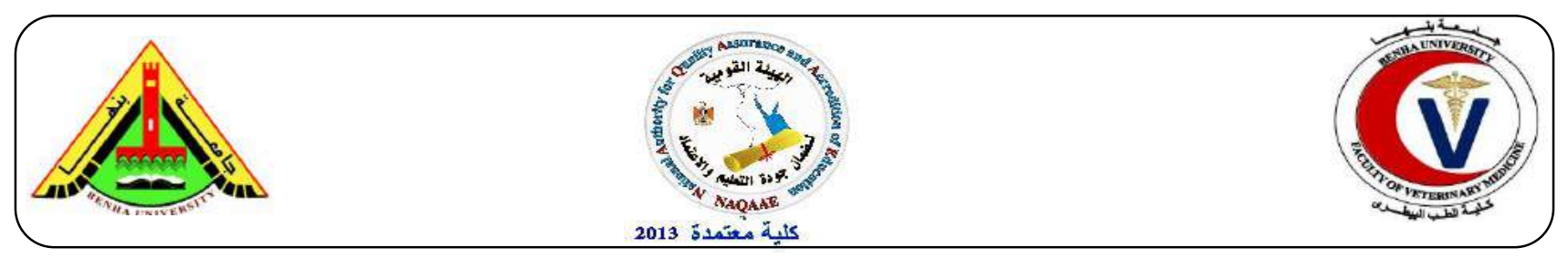

\title{
Hypolipidemic effects of barley- $\beta$-glucan in experimentally induced hyperlipidemic rats
}

\author{
Radwa Swelim, Ayman Samir Farid, Khalid Mostafa Fararh \\ Department of Clinical Pathology, Faculty of Veterinary Medicine, Benha University
}

\section{A B S T R A C T}

Dyslipidemia is one of the major risk factors for cardiac disease. We aimed to reduce this risk factor for lowering serum cholesterol levels by making dietary changes. Beta-glucan are glucose polymers present in cereal grains as barley, consumption of the whole grain or concentrated $\beta$-glucan preparation showed to lower blood lipid profile and atherogenic ratios. Fifty male albino rats were assigned into five groups. The control group received standard diet, the hyperlipidemic group fed $1 \%$ cholesterol and $20 \%$ coconut oil in the diet for 8 weeks. The $\beta$-glucan treated group received high fat diet for 4 weeks then high fat diet plus barley $\beta$-glucan $10 \mathrm{mg} /$ rats given orally for more 4 weeks. The $\beta$-glucan protected group received standard diet $+10 \mathrm{mg} / \mathrm{rat}$ barley $\beta$-glucan for 2 weeks then high fat diet + barley $\beta$-glucan $10 \mathrm{mg} /$ rat for another 8 weeks. The $\beta$-glucan group received standard diet + barley $\beta$-glucan $10 \mathrm{mg} / \mathrm{rat}$ for 8 weeks. The hyperlipidemic rats showed an increase in lipid profile, total lipid, phospholipids, atherogenic indices, liver enzymes, kidney functions and glucose level while a decrease in HDL-C and albumin compared with the control group. Moreover, histological examination of liver tissue of hyperlipidemic rats showed fatty hepatocytes compared with the control. Administration of barley $\beta$-glucan $10 \mathrm{mg} / \mathrm{rat}$ in treated and protected groups ameliorated the levels of lipids, atherogenic indices, liver functions, kidney functions and glucose. In addition, the liver tissues showed improved pathological alterations.

Keywords: $\beta$-glucan, hypolipidemic, hyperlipidemia, lipid profile, liver functions.

(http://www.bvmi.bu.edu.eg) (BVMJ-36(2): 13-23, 2019)

\section{INTRODUCTION}

Hyperlipidemia is a medical problem characterized by an increase in one or more of the plasma lipids, including triglycerides, cholesterol, cholesterol esters, phospholipids and/or plasma lipoproteins along with reduced high-density lipoprotein levels. This elevation of plasma lipids is a risk factor associated with cardiovascular diseases (CVDs) (Mishra et al., 2011). CVDs remain one of the substantial causes of death in the world. The major risk factors of CVDs are saturated fat, transfat intake; serum cholesterol and obesity. Diets recommended for improvement of cardiovascular risk factors include a diet high in dietary fiber (Queenan et al., 2007).

A logical strategy can be applied to prevent or treat cardiovascular disease is to target hyperlipidemia with chemical drugs and/or dietary intervention; there is a special focus on the hypolipidemic effects of dietary plants, 
some of which have been shown promising potential in lowering cholesterol levels in plasma (Zhu et al., 2010).

The addition of Barley $\beta$-glucan to diet cause a reduction in plasma total cholesterol and LDLcholesterol, barley can act as adjuvant therapeutics for improving serum parameters with metabolic regulation and lipid clearance of liver by promoting excretions of faecal lipids and bile acids (Abulnaja and El rabey, 2015).

This study aimed to investigate the effects of barley $\beta$-glucan on blood lipids, liver, kidney functions and glucose in rat fed high fat diet.

\section{MATERIALS AND METHODS}

\subsection{Animals:}

Adult male albino rats weighting 150-170 g obtained from the United Company for Chemicals (UCMA), El Salam city, Egypt. The animals were fed with standard diet and water ad libitum and housed for 7 days for acclimatization. Rats were divided into five groups (10 rats/group) and housed in separate cages. The study performed with approval from the institutional review board for animal experiments of the Faculty of Veterinary Medicine, Benha University.

\subsection{Chemicals used for experiment:}

Cholesterol powder $1 \%$ was obtained from Elbadr Company. The White Nile Street, Lebanon square, Giza, Egypt. Coconut oil 20\% obtained from Salsabil Company. Barely $\beta$ glucan obtained from Barely Beta-Glucan GLUCAGEL $^{\mathrm{TM}}$ is a trademark of DKSH Ltd which manufactured for Doctor`s Best, Inc. San Clemente, CA 92673. $10 \mathrm{mg} / \mathrm{rat}$ dissolved in $2 \mathrm{ml}$ distilled water.

\subsection{Experimental design:}

In this study, 50 adult male albino rats were divided into five groups (10 rats/group) as follow: group 1 (control group): served as control negative, rats fed standard diet for 8 weeks. Group 2 (Hyperlipidemic group) as a control positive which received high fat diet (standard diet +cholesterol $1 \%+$ coconut oil $20 \%$ ) for 8 weeks (Mohamed et al., 2010). Group 3 (treated group) received high fat diet for 4 weeks then high fat diet plus barley $\beta$ glucan $10 \mathrm{mg} / \mathrm{rats}$ taken orally for another 4 weeks (Salama, 2011). Group 4 (protected group) received standard diet $+10 \mathrm{mg} / \mathrm{rat}$ for 2 weeks then high fat diet + barley $\beta$-glucan 10 $\mathrm{mg} / \mathrm{rat}$ for another 8 weeks. Group 5 (barley group) received standard diet + barley $\beta$ glucan $10 \mathrm{mg} /$ rat for 8 weeks.

2.4. Sampling:

After overnight fasting blood samples were collected from retro-orbital venous plexus at the medial canthus of the eye using capillary tubes 5 rats from each group at the end of $4^{\text {th }}$ and $8^{\text {th }}$ week for separation of serum to be used in estimation of biochemical parameters: lipid profile "total cholesterol, triacylglycerol, HDL-c, LDL-c and VLDL-c" total lipids, phospholipids, liver enzymes "ALT and AST", albumin, kidney function tests "urea and creatinine" and glucose.

Liver tissue specimens were taken after sacrificing of rats from different groups at the end of 8th week of high fatty-diet then preserved in neutral buffered formalin $(10 \%)$ for histopathological examination.

\subsection{Biochemical parameters measurement:}

Total cholesterol was determined by the reaction described by Allain et al., (1974). Colorimetric determination of triacylglycerol was performed according to Fossati and Prencipe, (1982). HDL-cholesterol was determined by precipitation method according to Roeschlau et al., (1974). LDL-cholesterol was calculated according to the method described by Friedewald et al., (1972). The VLDL was determined as follow: VLDL= triacylglycerol/5 (Friedewald et al., 1972). The atherogenic indices were calculated as described by Bhardwaj et al., (2013). The atherogenic indices were calculated as following Castelli's Risk Index-I (CRI-I) = 
total cholesterol/HDL-C and Castelli's Risk Index-II (CRI-II) $=$ LDL-C/HDL-C as described by Bhardwaj et al., (2013). Atherogenic index of plasma (AIP) was calculated as AIP $=\log$ (triacylglycerol/HDLC) which described by Onat et al., (2010). Atherogenic coefficient was calculated as AC $=($ cholesterol - HDL-C $) /$ HDL-C which described by Ikewuchi, (2009). Triacylglycerol/HDL-C calculated according to Ranjit et al., (2015). The total lipids measured colorimetrically according to Chabrol and Castellano, (1961). Phospholipids was determined by the reaction described by Takayama et al., (1977). Kinetic determination of AST and ALT activity was performed according to (Schumann and Klauke, 2003). Colorimetric determination of albumin was performed according to Doumas et al., (1971). Urea was measured colorimetrically according to Kaplan, (1984). Kinetic determination of creatinine was measured according to Husdan and Rapoport, (1968). Glucose was performed according to Trinder, (1969).

\subsection{Histopathological examinations:}

Tissue samples were collected from rat's liver in all groups and fixed in neutral buffered formalin (10\%). Washing was done firstly by tap water then serial dilutions of alcohol (methyl, ethyl and absolute ethyl) for dehydration. Specimens were cleared by xylene then embedded in paraffin at $56^{\circ} \mathrm{C}$ in hot air oven for $24 \mathrm{hrs}$. Paraffin bees wax tissue blocks were prepared for sectioning at a thickness of 4 microns using sledge microtome. This tissue sections were collected on glass slides, deparaffinized and stained by Hematoxylin and Eosin (H\&E) stain (Bancroft et al., 1996) for histopathological examination through the light microscope.

\subsection{Statistical analysis:}

Data obtained were statistically evaluated for the mean and standard error (S.E). Statistical analysis was performed using the statistical software package SPSS for windows (Version
16.0: SPSS Inc., Chicago, III.). A value of $\mathrm{p}<0.05$ was considered statistically significant. Over all differences between groups were determined by one-way ANOVA.

\section{RESULTS}

\subsection{Plasma lipid level and atherogenic indices:}

The results presented in table (1) revealed that hyperlipidemic rats (group2) showed significant increase in the concentrations of plasma total cholesterol, triglycerides, LDL-C, VLDL-C, Total lipids, phospholipids and atherogenic indices "CRI-I, CRI-II, AIP, AC and Triglycerides/HDL-C" at 8th weeks when compared with control rats (group1). Administration of barley $\beta$-glucan in treated (group3) and protected (group4) groups showed significant decreases in their levels compared with hyperlipidemic group (group2). Whereas HDL-C showed significant decrease in hyperlipidemic rats compared with control negative rats (group1), while there is a significant increase in HDL-C in rats of treated (group3) and protected (group4) with barley $\beta$ glucan compared to hyperlipidemic rats.

\subsection{Biochemical parameters:}

The results presented in table (2) revealed that hyperlipidemic rats (group2) showed significant increase in ALT, AST, urea, creatinine and glucose with significant decrease in albumin level compared with control rats (group1). Administration of barley $\beta$-glucan in treated (group3) and protected (group4) groups showed significant decreases in ALT, AST, urea, creatinine and glucose levels with significant increase in albumin compared with hyperlipidemic group (group2).

\subsection{Histopathology of the liver:}

The liver of control rats showed normal histological structures of the central vein with 
the surrounding hepatocytes in the parenchyma shown in figure (1A).

The pathological findings in hyperlipidemic group were severe dilatation in the central and portal veins associated with apoptosis in the hepatocytes in the parenchyma surrounding the portal area and there was karyomegaly in the nuclei of some individual hepatocytes. Congestion of hepatic sinusoids with diffuse infiltration of inflammatory cells in between the hepatocytes. Fatty change in the hepatocytes is in diffuse manner all over the parenchyma with intracytoplasmic fat vacuoles and signet ring appearance (figure 1B).

Treated rats with barley $\beta$-glucan showed congestion in the central and portal veins associated with ballooning degeneration in the hepatocytes at the periphery of the lobules. The portal area showed inflammatory cells infiltration with ballooning degeneration of hepatocytes (figure 1C).

Protected rats with barley $\beta$-glucan showed Ballooning degeneration in the hepatocytes, while the portal area showed dilatation and congestion of the portal vein with oedema and inflammatory cells infiltration around the bile ducts (figure 1D).

Barley $\beta$-glucan group showed no histological alteration (figure 1E).

Table1: changes of Lipid parameters and atherogenic ratios in control, hyperlipidemic, treated, protected and barley groups after 8 weeks.

\begin{tabular}{|c|c|c|c|c|c|}
\hline \multirow[t]{2}{*}{ Parameters } & Control & \multicolumn{2}{|c|}{ Hyperlipidemic Treated } & \multirow{2}{*}{$\begin{array}{l}\text { Protected } \\
\text { Group }\end{array}$} & \multirow{2}{*}{$\begin{array}{l}\text { Barley } \\
\text { Group }\end{array}$} \\
\hline & Group & Group & Group & & \\
\hline T. cholesterol (mg/dl) & $82.6 \pm 1.85^{\mathrm{c}}$ & $159.00 \pm 2.3^{\mathrm{a}}$ & $130.00 \pm 1.60^{\mathrm{b}}$ & $120.60 \pm 6.92^{b}$ & $59.40 \pm 3.52^{\mathrm{d}}$ \\
\hline Triacylglycerol (mg/dl) & $84.2 \pm 2.6^{\mathrm{d}}$ & $155.8 \pm 1.28^{\mathrm{a}}$ & $127.60 \pm 2.73^{b}$ & $118.80 \pm 2.54^{\mathrm{c}}$ & $54.00 \pm 1.84^{\mathrm{e}}$ \\
\hline HDL (mg/dl) & $30.26 \pm 1.71^{\mathrm{a}}$ & $14.84 \pm 0.85^{\mathrm{c}}$ & $20.68 \pm 0.30^{\mathrm{b}}$ & $20.04 \pm 0.71^{b}$ & $22.10 \pm 1.83^{\mathrm{ab}}$ \\
\hline $\mathrm{LDL}(\mathrm{mg} / \mathrm{dl})$ & $33.5 \pm 1.26^{\mathrm{d}}$ & $113.00 \pm 2.82^{\mathrm{a}}$ & $91.80 \pm 1.66^{\mathrm{b}}$ & $75.80 \pm 1.41^{\mathrm{c}}$ & $26.5 \pm 1.16^{\mathrm{d}}$ \\
\hline VLDL (mg/dl) & $16.84 \pm 0.52^{d}$ & $31.16 \pm 0.66^{\mathrm{a}}$ & $25.52 \pm 0.55^{b}$ & $23.76 \pm 0.51^{\mathrm{c}}$ & $12.80 \pm 0.37^{\mathrm{e}}$ \\
\hline Total lipids (mg/dl) & $303.4 \pm 8.1^{\mathrm{d}}$ & $569.2 \pm 23.71^{\mathrm{a}}$ & $479.20 \pm 19.17^{\mathrm{b}}$ & $441.80 \pm 17.40^{c}$ & $262.80 \pm 15.89^{\mathrm{e}}$ \\
\hline Phospholipids (mg/dl) & $45 \pm 1.52^{\mathrm{d}}$ & $85 \pm 1.54^{\mathrm{a}}$ & $71.00 \pm 1.36^{\mathrm{b}}$ & $66.20 \pm 1.6^{c}$ & $30.80 \pm 0.97^{\mathrm{e}}$ \\
\hline CRI-I & $2.72 \pm 0.36^{\mathrm{c}}$ & $10.71 \pm 0.49^{\mathrm{a}}$ & $6.28 \pm 0.41^{\mathrm{b}}$ & $6.01 \pm 0.36^{\mathrm{b}}$ & $2.23 \pm 0.26^{c}$ \\
\hline CRI-II & $1.10 \pm 0.13^{\mathrm{c}}$ & $7.61 \pm 0.43^{\mathrm{a}}$ & $4.43 \pm 0.36^{\mathrm{b}}$ & $3.78 \pm 0.26^{\mathrm{b}}$ & $1.19 \pm 0.09^{c}$ \\
\hline $\mathrm{AC}$ & $1.72 \pm 0.33^{\mathrm{c}}$ & $9.71 \pm 0.56^{\mathrm{a}}$ & $5.28 \pm 0.43^{\mathrm{b}}$ & $5.01 \pm 0.39^{\mathrm{b}}$ & $1.68 \pm 0.13^{\mathrm{c}}$ \\
\hline AIP & $0.084 \pm 0.01^{\mathrm{c}}$ & $0.661 \pm 0.03^{\mathrm{a}}$ & $0.430 \pm 0.03^{b}$ & $0.413 \pm 0.02^{b}$ & $0.028 \pm 0.01^{\mathrm{d}}$ \\
\hline TG/HDL-C & $2.78 \pm 0.31^{\mathrm{c}}$ & $10.49 \pm 0.49^{\mathrm{a}}$ & $6.17 \pm 0.41^{\mathrm{b}}$ & $5.92 \pm 0.36^{\mathrm{b}}$ & $2.44 \pm 0.16^{\mathrm{c}}$ \\
\hline
\end{tabular}

a, b, c, d \& e : Superscripts to compared statistically within the same row. Values with different letter superscripts are significantly different $(p<0.05)$. 
Table 2: changes of liver, renal and glucose in control, hyperlipidemic, treated, protected and barley groups after 8 weeks.

\begin{tabular}{llllll}
\hline $\begin{array}{l}\text { Groups } \\
\text { Parameters }\end{array}$ & $\begin{array}{l}\text { Control } \\
\text { Group1 }\end{array}$ & $\begin{array}{l}\text { Hyperlipidemic } \\
\text { Group2 }\end{array}$ & $\begin{array}{l}\text { Treated } \\
\text { Group3 }\end{array}$ & $\begin{array}{l}\text { Protected } \\
\text { Group4 }\end{array}$ & $\begin{array}{l}\text { Barley } \\
\text { Group5 }\end{array}$ \\
\hline AST (U/L) & $109.33 \pm 5.92^{\mathrm{d}}$ & $226.80 \pm 4.41^{\mathrm{a}}$ & $170.33 \pm 7.68^{\mathrm{b}}$ & $159.6 \pm 9.81^{\mathrm{c}}$ & $107.65 \pm 4.84^{\mathrm{d}}$ \\
$\begin{array}{l}\text { ALT (U/L) } \\
\text { Albumin }\end{array}$ & $69.8 \pm 2.8^{\mathrm{d}}$ & $132.8 \pm 5.19^{\mathrm{a}}$ & $103.67 \pm 4.15^{\mathrm{b}}$ & $96.00 \pm 2.08^{\mathrm{c}}$ & $62.75 \pm 1.07^{\mathrm{d}}$ \\
$\begin{array}{l}\text { (g/dl) } \\
\text { Urea (mg/dl) }\end{array}$ & $23.6 \pm \pm 1.75^{\mathrm{c}}$ & $44.2 \pm 2.18^{\mathrm{a}}$ & $32.66 \pm 0.92^{\mathrm{b}}$ & $30.33 \pm 1.33^{\mathrm{b}}$ & $22.33 \pm 1.95^{\mathrm{c}}$ \\
$\begin{array}{l}\text { Creatinine } \\
(\mathrm{mg} / \mathrm{dl})\end{array}$ & $0.38 \pm 0.03^{\mathrm{c}}$ & $0.68 \pm 0.03^{\mathrm{a}}$ & $0.53 \pm 0.03^{\mathrm{b}}$ & $0.49 \pm 0.02^{\mathrm{b}}$ & $0.39 \pm 0.03^{\mathrm{c}}$ \\
$\begin{array}{l}\text { Glucose } \\
(\mathrm{mg} / \mathrm{dl})\end{array}$ & $74.6 \pm 4.18^{\mathrm{c}}$ & $148.00 \pm 4.55^{\mathrm{a}}$ & $108.00 \pm 7.23^{\mathrm{b}}$ & $111.00 \pm 5.03^{\mathrm{b}}$ & $72.00 \pm 2.86^{\mathrm{c}}$ \\
\hline
\end{tabular}

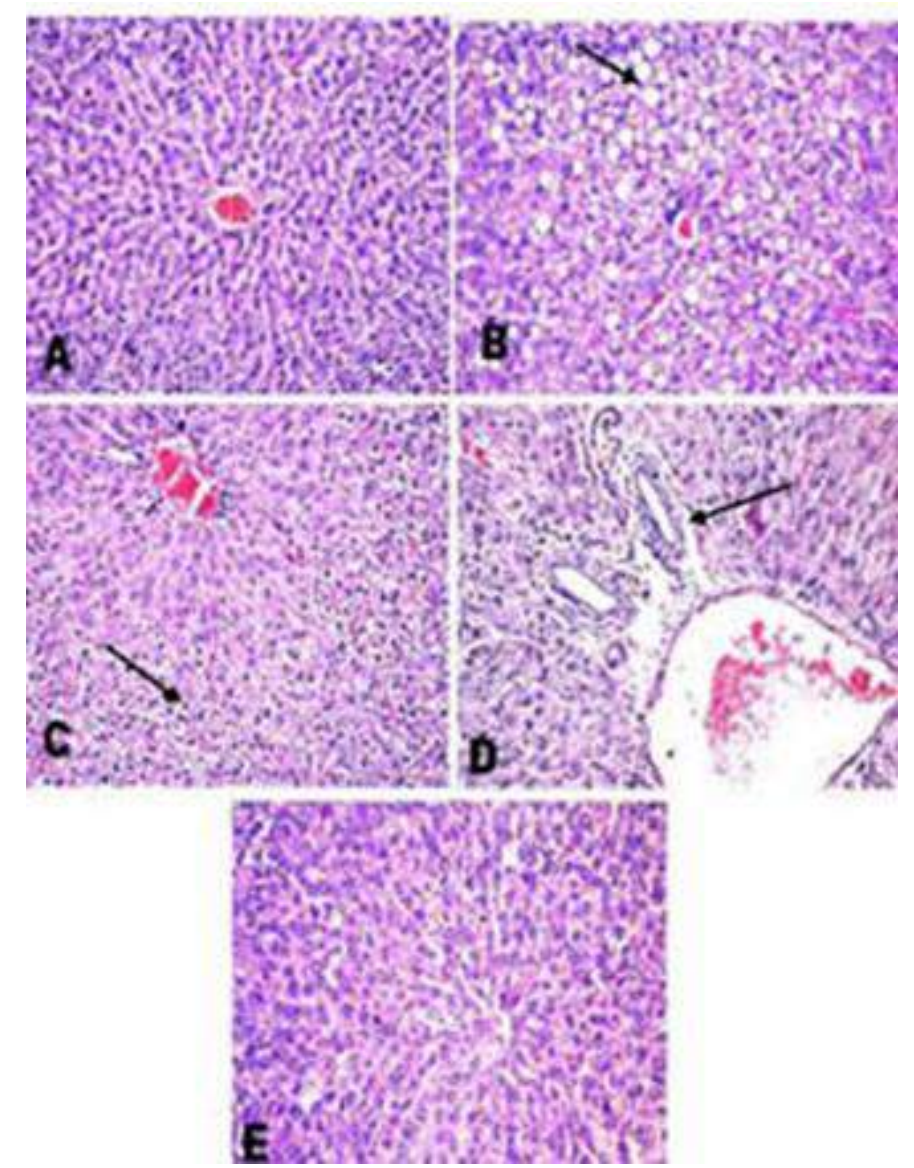

Fig.1.A: hepatocytes of normal rats ; B: hepatocytes of hyperlipidemic rats showed fatty change in the hepatocytes (arrow), congestion in the hepatic sinusoids associated with diffuse inflammatory cells infiltration in between the hepatocytes; $C$ : hepatocytes of hyperlipidemic rats + barley $\beta$-glucan showed inflammatory cells infiltration with ballooning degeneration in the hepatocytes; $D$ : hepatocytes of hyperlipidemic rats protected barley $\beta$-glucan showed dilatation and congestion in the portal vein with oedema and inflammatory cells infiltration surrounding the bile ducts ; E: hepatocytes of normal rats + barley $\beta$-glucan showed no histological alteration. 


\section{DISCUSSION}

In the present study, feeding rats $1 \%$ cholesterol $+20 \%$ coconut oil in the diet for 8 weeks increased the serum total cholesterol and induced hypercholesterolemia in (group2). These results run parallel to Barakat and Mahmoud, (2011); Abulnaja and El Rabey, (2015); Aly-Aldin et al., (2015); Adekunle et al., (2014) and Nammi et al., (2009). Increased uptake of exogenous cholesterol and subsequent deposition and decreased cholesterol catabolism as stated by a reduction in bile acid production and turnover of bile acids (Shah et al., 2001). Marked increase in the serum total cholesterol and triglycerides may be due to enhanced cholesterol biosynthesis during high intake of fatty diet (Jones, 1997).

The concurrent oral administration of barley $\beta$ glucan to the hyperlipidemic rats of treated and protected groups for 8 weeks significantly improved the serum lipid profile parameters. This result is consistent with Wang et al., (2015) and El rabey et al., (2013). Betaglucans have hypocholesterolemic effects and help in reduce atherogenic indices; the mechanism is reducing the intestinal absorption of cholesterol and bile acids by binding to glucans; so, shifting the liver from cholesterol syntheses to bile acid production. Fermentation by intestinal bacteria to shortchain fatty acids, which are absorbed and inhibit hepatic cholesterol syntheses (Sofi et al., 2017). The binding of cholesterol with beta-glucan and the resulting elimination of these molecules in the feces is helps reduce blood cholesterol (Yun et al., 2003). The amelioration of blood lipid profile may be due to decreased absorption of bile acids that cause a removal of steroids from the body by fecal excretion resulting in increased catabolism of cholesterol, an increase in the secretion of bile acids, a decrease in lipoprotein cholesterol secretion, and a reduction in the total body pool of cholesterol (Malkki, 2001).

Furthermore, liver enzymes (ALT and AST) were significantly increased under induced hyperlipidemic condition in male rats compared to control group. A similar effect was observed by De Miranda et al., (2014) and Wang et al., (2013). Excessive accumulation of lipids in hepatocytes due to an imbalance between lipid formation and lipid degradation (Burt et al., 1998), caused the increased levels of aminotransferases result from leakage from damaged hepatic cells and can be used as markers of liver injury (Giannini et al., 2005).

The supplementation with barley $\beta$-glucan to the hyperlipidemic rats in treated and protected group has significantly ameliorated the liver enzymes. This result is consistent with Nehal and Belal, (2011) and Yu et al., (2002). This may be due to the observed decrease in fat accumulation in the liver that suggested the decrease in hepatic TAG synthesis by a reduction of fatty acid synthase ( $\mathrm{Lu}$ and Archer, 2007). There is a significant decrease in albumin level in hyperlipidemic group compared to control group. This result agrees with Moneim et al., (2014) and Ghasi et al., (2000).Reducing in protein might be attributed to decrease in protein uptake from the intestine due to high-calorie lipid diet; this is an indication of diminished synthetic function of the liver which may results from hepatocellular injury or stress resulting from the increased metabolic need for tissue repair and free radical neutralization occasioned by the high fat diet (Nwozo et al., 2017). While, Treated and protected groups with barley $\beta$-glucan showed significant increase in albumin level compared to hyperlipidemic group. This result parallel with Quan et al., (2018) who proved pretreatment with barley enhances albumin level.

Concerning to kidney function changes; hyperlipidemic group indicated a significant 
increase in urea and creatinine levels comparing to control group after 8 weeks of high fat diet. These results agree with Barakat and Mahmoud, (2011). The hypercholesterolemia leads to reduced renal blood flow and increased renal vascular resistance which are factors directly related with the impairment of renal function (Gervais et al., 2003). On the other hand, treated and protected rats with barley $\beta$-glucan groups showed significant decrease in urea and creatinine levels when compared to hyperlipidemic group. These results agree with El rabey et al., (2013). This result may be due to $\beta$-glucan protects the tubular epithelium effectively from injury as $\beta$-glucan has antioxidant capacity it attenuated the renal injury (Bayrak et al., 2008).

In addition, serum glucose level; hyperlipidemic group indicated a significant increase in glucose level comparing to control group. These results agree with Aly-Aldin et al., (2015).Glucose level was significantly increased in high fat diet (HFD) in rats because of glucose-fatty acid cycle (Randle et al., 1963), where the high free fat acid (FFA) reduce the glucose uptake and utilization, through the increased endogenous glucose production (Song et al., 2002). On the other hand, treated and protected groups with barley $\beta$-glucan showed significant decrease in glucose level compared to hyperlipidemic group. These results agree with Brockman et al., (2013).The amelioration of glucose response of barley $\beta$-glucan is attributed to the well-formed protein-starch matrix then strong and continuous protein strands entrapping large starch granules. The entrapment of starch reduces accessibility to enzymatic degradation and hence reduces sugar liberation (Cleary and Brennan, 2006).

The hepatic tissues were significantly affected in hyperlipidemic rats of group2 showed severe dilatation in the central and portal veins associated with apoptosis in the individual hepatocytes in the parenchyma surrounding the portal area. Congestion of the hepatic sinusoids associated with diffuse inflammatory cells infiltration in between the hepatocytes. Fatty hepatocytes in diffuse manner all over the parenchyma with intracytoplasmic fat vacuoles and signet ring appearance. This result in consistent with other studies showed a correlation between hyperlipidemia and pathological alteration in liver (Abulnaja and El Rabey, 2015).

The supplementation with barley $\beta$-glucan in treated and protected rats in group 3 and 4 has significantly improved the liver tissues with portal area showed less inflammatory cells infiltration with ballooning degeneration of hepatocytes. This result agreed with Nehal and Belal, (2011).

\section{Conclusion}

It is concluded that barley $\beta$-glucan succeeded in lowering hyperlipidemia induced by high fat diet for 8 weeks in male rats by lowering TC, TAG, LDL-C, VLDL-C, total lipids, phospholipids and atherogenic indices treated and protected groups. Barley $\beta$-glucan supplementation has also improved liver functions, kidney functions and glucose.

\section{REFERENCES}

Abulnaja, K.O. and El Rabey, H.A., 2015. The efficiency of barley (hordeumvulgare) bran in ameliorating blood and treating fatty heart and liver of male rats. Evidence-Based Complementary and Alternative Medicine 2015, 13.

Adekunle, A., Oluba, A., Babatola, L., Kamdem, J. and Adesokan, A., 2014. Antiatherogenic, hypolipidemic and antiinflammatory benefits of black tea and Zanthoxylumzanthoxyloid. British 
Journal of Medicine and Medical Research 4, 1923-1937.

Allain, C.C., Poon, L.S., Chan, C.S., Richmond, W. and Fu, P.C., 1974. Enzymatic determination of total serum cholesterol. Clinical chemistry 20, 470475.

Aly-Aldin, M.M., Mansour, E.H., Rahma, E.H., El, A.E.E.-B.A., ElBedawey, F.A. and El-Habashy, M.M., 2015. Protective role of flaxseed oil on hypercholesterolemic rats. Biolife 3: 794-801.

Bancroft, J., Stevens, A. and Turner, D., 1996.Theory and practice of histological techniques 4th Ed Churchill Living Stone, New York Edinburgh. Madrid, Sanfrancisco.

Barakat, L.A. and Mahmoud, R.H., 2011. The antiatherogenic, renal protective and immunomodulatory effects of purslane, pumpkin and flax seeds on hypercholesterolemic rats. North American journal of medical sciences 3 , 411-417.

Bayrak, O., Turgut, F., Karatas, O.F., Cimentepe, E., Bayrak, R., Catal, F., Atis, O., Akcay, A. and Unal, D., 2008. Oral $\beta$-glucan protects kidney against ischemia/reperfusion injury in rats. American Journal of Nephrology 28, 190-196.

Bhardwaj, S., Bhattacharjee, J., Bhatnagar, M. and Tyagi, S., 2013. Atherogenic index of plasma, castelli risk index and atherogenic coefficient-new parameters in assessing cardiovascular risk. Int $J$ Pharm BiolSci 3, 359-364.

Brockman, D.A., Chen, X. and Gallaher, D.D., 2013. Consumption of a high $\beta$-glucan barley flour improves glucose control and fatty liver and increases muscle acylcarnitines in the Zucker diabetic fatty rat. European journal of nutrition 52, 1743-1753.

Burt, A.D., Mutton, A. and Day, C.P., 1998. Diagnosis and interpretation of steatosis and steatohepatitis. Seminars in diagnostic pathology, pp. 246-258.

Chabrol, E. and Castellano, A., 1961. SPV method for estimation of total serum lipid. J. Lab. Clin. Med 57, 300.

Cleary, L. and Brennan, C., 2006. The influence of a $(1 \rightarrow 3)(1 \rightarrow 4)-\beta$-dglucan rich fraction from barley on the physico-chemical properties and in vitro reducing sugars release of durum wheat pasta. International journal of food science \& technology 41, 910-918.

de Miranda, A.M., Ribeiro, G.M., Cunha, A.C., Silva, L.S., dos Santos, R.C., Pedrosa, M.L. and Silva, M.E., 2014. Hypolipidemic effect of the edible mushroom Agaricusblazei in rats subjected to a hypercholesterolemic diet. Journal of physiology and biochemistry 70, 215-224.

Doumas, B.T., Watson, W.A. and Biggs, H.G., 1971. Albumin standards and the measurement of serum albumin with bromcresol green. Clinicachimicaacta 31, 87-96.

El Rabey, H.A., Al-Seeni, M.N. and Amer, H.M., 2013. Efficiency of barley bran and oat bran in ameliorating blood lipid profile and the adverse histological changes in hypercholesterolemic male rats. BioMed research international 2013, 10.

Fossati, P. and Prencipe, L., 1982. Serum triglycerides determined colorimetrically with an enzyme that 
produces hydrogen peroxide. Clinical chemistry 28, 2077-2080.

Friedewald, W.T., Levy, R.I. and Fredrickson, D.S., 1972. Estimation of the concentration of low-density lipoprotein cholesterol in plasma, without use of the preparative ultracentrifuge. Clinical chemistry 18, 499-502.

Gervais, M., Pons, S., Nicoletti, A., Cosson, C., Giudicelli, J.-F. and Richer, C., 2003. Fluvastatin prevents renal dysfunction and vascular NO deficit in apolipoprotein E-deficient mice. Arteriosclerosis, thrombosis, and vascular biology 23, 183-189.

Ghasi, S., Nwobodo, E. and Ofili, J., 2000. Hypocholesterolemic effects of crude extract of leaf of Moringaoleifera Lam in high-fat diet fed Wistar rats. Journal of Ethnopharmacology 69, 21-25.

Giannini, E.G., Testa, R. and Savarino, V., 2005. Liver enzyme alteration: a guide for clinicians. Cmaj 172, 367-379.

Husdan, H. and Rapoport, A., 1968. Estimation of creatinine by the Jaffe reaction: a comparison of three methods. Clinical chemistry 14, 222-238.

Ikewuchi, C., 2009. Alteration of plasma lipid profiles and atherogenic indices by Stachytarphetajamaicensis L.(Vahl). Biokemistri 21, 71-77.

Jones, P., 1997. Regulation of cholesterol biosynthesis by diet in humans. The American journal of clinical nutrition66, 438-446.

Kaplan, L.A., 1984. Urea. In Clinical Chemistry: Theory, Analysis, and Correlation, L.A. Kaplan and A.J. Pesce,
Eds. C.V. Mosby, St. Louis, MO, $1257-$ 1260.

Lu, S. and Archer, M.C., 2007. Celecoxib decreases fatty acid synthase expression via down-regulation of c-Jun Nterminal kinase-1. Experimental biology and medicine 232, 643-653.

Malkki, Y., 2001. Oat fiber: production, composition, physicochemical properties, physiological effects, safety, and food applications. Food Science and Technology-New York-Marcel Dekker-, 497-518.

Mishra, P.R., Panda, P.K., Korla, A. and Panigrahi, S., 2011. Evaluation of acute hypolipidemic activity of different plant extracts in Triton WR-1339 induced hyperlipidemia in albino rats. Pharmacologyonline 3, 925-934.

Mohamed, D.A., Hamed, T.E. and Al-Okbi, S.Y., 2010. Reduction in hypercholesterolemia and risk of cardiovascular diseases by mixtures of plant food extract: a study on plasma lipid profile, oxidative stress and testosterone in rats. Grasas y aceites 61, 378-389.

Moneim, A.A., Mahmoud, B. and Mahmoud, R., 2014. The effect of fish oil supplementation on the liver and kidney functions of hyperlipidemic and hypothyroid albino rats. International Journal of Bio-Pharma Research 3, 230-236.

Nammi, S., Sreemantula, S. and Roufogalis, B.D., 2009. Protective effects of ethanolic extract of Zingiberofficinale rhizome on the development of metabolic syndrome in high-fat diet-fed rats. Basic \& clinical pharmacology \& toxicology 104, 366-373. 
Nehal, M. and Belal, A., 2011. Hepatoprotective effect of feeding celery leaves mixed with Chicory leaves and Barley Grains to hypercholesterolemic rats. Asian J Clin Nutrition 3, 14-24.

Nwozo, S.O., Lewis, Y.T. and Oyinloye, B.E., 2017. The effects of Piper guineense versus Sesamumindicum aqueous extracts on lipid metabolism and antioxidants in hypercholesterolemic rats. Iranian journal of Medical Sciences 42, 449-456.

Onat, A., Can, G., Kaya, H. and Hergenç, G., 2010. "Atherogenic index of plasma" ( $\log 10 \quad$ triglyceride/high-density lipoprotein- cholesterol) predicts high blood pressure, diabetes, and vascular events. Journal of clinical lipidology 4 , 89-98.

Quan, M., Li, Q., Zhao, P. and Tian, C., 2018. Chemical composition and hepatoprotective effect of free phenolic extract from barley during malting process. Scientific reports 8, 4460 .

Queenan, K.M., Stewart, M.L., Smith, K.N., Thomas, W., Fulcher, R.G. and Slavin, J.L., 2007. Concentrated oat $\beta$-glucan, a fermentable fiber, lowers serum cholesterol in hypercholesterolemic adults in a randomized controlled trial. Nutrition Journal 6, 6.

Randle, P., Garland, P., Hales, C. and Newsholme, E., 1963. The glucose fatty-acid cycle its role in insulin sensitivity and the metabolic disturbances of diabetes mellitus. The Lancet 281, 785-789.

Ranjit, P.M., Guntuku, G.S. and Pothineni, R.B., 2015. New atherogenic indices: Assessment of cardio vascular risk in post-menopausal dyslipidemia. Asian Journal of Medical Sciences 6, 25-32.

Roeschlau, P., Bernt, E. and Gruber, W., 1974. Enzymatic determination of total cholesterol in serum. Zeitschrift fur klinischeChemie und klinischeBiochemie 12, 226-226.

Salama, S.F., 2011. Beta-glucan ameliorates gamma-rays induced oxidative injury in male swiss albino rats. Pakistan Journal of Zoology 43, 933-939.

Schumann, G. and Klauke, R., 2003.New IFCC reference procedures for the determination of catalytic activity concentrations of five enzymes in serum: preliminary upper reference limits obtained in hospitalized subjects. Clinicachimica acta327, 69-79.

Shah, P.K., Kaul, S., Nilsson, J. and Cercek, B., 2001. Exploiting the vascular protective effects of high-density lipoprotein and its apolipoproteins: an idea whose time for testing is coming, part I. Circulation $104,2376-2383$.

Sofi, S., Singh, J. and Rafiq, S., 2017. $\beta$ Glucan and Functionality: A Review. EC Nutrition 10, 67-74.

Song, H., Shojima, N., Sakoda, H., Ogihara, T., Fujishiro, M., Katagiri, H., Anai, M., Onishi, Y., Ono, H. and Inukai, K., 2002. Resistin is regulated by C/EBPs, PPARs, and signal-transducing molecules. Biochemical and biophysical research communications 299, 291-298.

Takayama, M., Itoh, S., Nagasaki, T. and Tanimizu, I., 1977. A new enzymatic method for determination of serum choline-containing phospholipids. Clinicachimicaacta 79, 93-98. 
Trinder, P., 1969.Determination of glucose in blood using glucose oxidase with an alternative oxygen acceptor. Annals of clinical Biochemistry6, 24-27.

Wang, Y., Harding, S.V., Eck, P., Thandapilly, S.J., Gamel, T.H., Abdel-Aal, E.-S.M., Crow, G.H., Tosh, S.M., Jones, P.J. and Ames, N.P., 2015. High-MolecularWeight $\beta$-Glucan Decreases Serum Cholesterol Differentially Based on the CYP7A1 rs3808607 Polymorphism in Mildly Hypercholesterolemic Adults-3. The Journal of nutrition 146, 720-727.

Wang, Z., Bao, Y., Zhang, Y., Zhang, J., Yao, G., Wang, S. and Zhang, H., 2013. Effect of soymilk fermented with Lactobacillus plantarum P-8 on lipid metabolism and fecal microbiota in experimental hyperlipidemic rats. Food Biophysics 8, 43-49.

Yu, Y.-M., Wu, C.-H., Tseng, Y.-H., Tsai, C.E. and Chang, W.-C., 2002. Antioxidative and hypolipidemic effects of barley leaf essence in a rabbit model of atherosclerosis. The Japanese Journal of Pharmacology 89, 142-148.

Yun, C.-H., Estrada, A., Van Kessel, A., Park, B.-C. andLaarveld, B., 2003. $\beta$-Glucan, extracted from oat, enhances disease resistance against bacterial and parasitic infections. FEMS Immunology \& Medical Microbiology 35, 67-75.

Zhu, X., Zhang, W., Zhao, J., Wang, J. and Qu, W., 2010. Hypolipidaemic and hepatoprotective effects of ethanolic and aqueous extracts from Asparagus officinalis L. by-products in mice fed a high-fat diet. Journal of the Science of Food and Agriculture 90, 1129-1135. 